\title{
Guilt and elation in the workplace: Emotion and the governance of the environment at
}

$$
\text { work }
$$

\section{REBECCA WHITTLE}

\begin{abstract}
This paper explores the integration of environmental concern into the workplace by combining insights from the literature on governmentality with work which focuses on the role of emotion in organizational contexts. I build on work by Hargreaves (2008) and Butler (2010) to show that environmental concern is an emerging form of workplace governance which acts by and through the emotions and which intersects with pre-existing forms of power in surprising and complex ways. I conclude by reflecting on some additional theoretical approaches which may offer some tools for developing forms of workplace governance which are more socially and environmentally sustainable.
\end{abstract}

Key Words: Morality, Governmentality, Workplace, Behaviour Change

\section{Prologue: The milk bottle and the recycling bin}

Several years ago, a new recycling bin for milk bottles appeared in our office kitchen as part of campus-wide changes to recycling provision. A few weeks after the bin was installed I arrived in the kitchen early one morning to discover an irate, anonymous note from another kitchen user had been placed on the cupboard above the sink, stating that plastic bottles had now been removed from the regular bin three times (this really was underlined) and reminding people that this was extremely poor practice for a building that was supposed to be an environment centre, particularly since the new recycling bin was immediately next to the residual waste bin. 
This is a pre-copy-editing PDF of an article accepted 20 Sep 2013 following peer review for publication in Environmental Values 24 (2015): 581-601. doi: 10.3197/096327114X13947900182111

(C)The White Horse Press http://www.whpress.co.uk

It struck me that this was the first time that someone had felt the need to write an angry note about an environmental issue in our workplace kitchen. Similar notes had appeared previously but these were always in protest at the general lack of cleanliness exhibited in the shared space. But imagine, for a moment, that you are a fellow user of our kitchen: - how would you react to the note? Would you side with the anonymous note writer and feel angry at the miscreant who is failing to use the recycling bin? Smug that you already use the new bin and thus are not the guilty party? Guilty because you remember that you used the wrong bin twice last week and didn't bother to correct your mistake? Or angry and defensive? The environment police should mind their own business! Perhaps you'd feel a combination of these, or something else entirely. In the end, it matters little. The key point in the context of the present paper is that there is a governance - and thus a politics - to the micro practices of everyday life in the workplace, with environmental concerns playing an increasingly important role. Crucially, these forms of governance are also inherently emotional in how they are felt, communicated and experienced, as the milk bottle incident illustrates rather well...

\section{Introduction}

This article uses the example of governance by and through the emotions to explore the implications of the ways in which environmental concern is integrated into the workplace. Building on the work of Hargreaves (2008) it shows environmental concern to be a new and equally emotive form of governance which enmeshes with existing forms of workplace governmentality in surprising and complex ways (Hargreaves, 2008). Through exploring people's experiences of guilt, elation and everything in between, I illustrate what happens when these two forms of governmentality come together and highlight the kinds of hidden emotional work that individuals use to negotiate between the competing forms of power that are produced and exercised through their interactions. Such an analysis reveals the ways in which both governance processes and the emotions are inherently relational. For this reason, I conclude by arguing that 
This is a pre-copy-editing PDF of an article accepted 20 Sep 2013 following peer review for publication in Environmental Values 24 (2015): 581-601. doi: 10.3197/096327114X13947900182111

(C)The White Horse Press http://www.whpress.co.uk

it is both unfair and unrealistic to expect individuals to be able to negotiate conflicts between environmental and pre-existing forms of workplace governance. Instead, I highlight some additional theoretical tools which may help develop forms of governance which are more socially and environmentally sustainable.

To illustrate my key points, this article interweaves theoretical discussion with qualitative data generated as part of Current, a two-year, EPSRC funded study of energy use in large office environments, which is described in more detail in the following section.

\section{Introducing Current}

Current did not originally set out to explore the specific issues discussed in this paper. Rather, our aim was to develop a multi-disciplinary project which combined computer science and social science expertise to explore energy-use -particularly computer/IT energy use - in large office environments. Our case study site for the research was the large office environment of Lancaster University.

Focused on our original aim, we pursued a mixed methods approach, which combined interviews and group work with office energy monitoring via specially designed software as well as hardware data loggers. The discussion in this paper is based solely upon the 21 semi structured interviews which were conducted for the project in the autumn of 2011.

These were carried out with staff and $\mathrm{PhD}$ students who self selected themselves from a larger pool of 200 volunteers who signed up to a project mailing list generated during a summer recruitment drive. Inspired by a practice-based approach (Shove, 2003, Hitchings, 2012), the interviews were not centred around the subject of energy per se - rather they focussed on the nature of daily life at work in terms of the types of practices that people engaged in and the kinds of technologies that they interacted with. We then employed an approach to the analysis which was broadly derived from grounded theory (Glaser, 1992). This consisted of a series of 
workshops with the project team where we went through samples of the interview transcripts collectively and noted down all the themes and ideas that emerged for us.

It was at this point that our focus on governance and emotion emerged in bottom-up fashion from the data as we realized that the contemporary workplace was brimful of emotion.

Seemingly small matters like leaving computers on overnight, driving to work when you could cycle or take the bus, or remembering to turn off the office lights at the end of the day, appeared to provoke strong emotional reactions among interviewees. Such instances were often described as 'infuriating', 'lazy', 'good' or 'slack' (Butler, 2010).

Such a realization encouraged us to reinterpret the data that we had generated on environmental practices at work in the light of insights stemming from two largely separate bodies of literature; the governmentality literature associated with the work of Foucault, Rose and others, and work focussing on the role of emotion management in organizational contexts.

In addition to shedding new light on the research findings, this work also enabled us to map the synergies between these two bodies of literature, allowing us to show that workplace governmentality is relational, and that it operates by and through the emotions. This is the argument that I lay out in the first sections of this paper, which consider governmentality and emotion in turn.

Starting from this broad canvas I then turn to the more detailed picture of how new forms of governmentality related to the environment act relationally through the emotions to enmesh with these pre-existing forms of governance (Hargreaves 2008). In response to the conflicts exposed by this discussion, I conclude by reflecting on some additional theoretical approaches which could help foster a more socially and environmentally sustainable culture at work. 
This is a pre-copy-editing PDF of an article accepted 20 Sep 2013 following peer review for publication in Environmental Values 24 (2015): 581-601. doi: 10.3197/096327114X13947900182111

(C)The White Horse Press http://www.whpress.co.uk

First, though, I turn to the governmentality literature for a better understanding of how people quite literally 'work on themselves at work' as they attempt to produce themselves as responsible, productive and successful neo-liberal employees.

\section{Governmentality at work: Trying to be a 'productive' employee}

The idea of the 'productive', successful employee, which is explored in this section, proved useful in trying to understand a curious contradiction emerging from the interviews: the fact that those who, on the face of it, might be expected to experience more freedom within the workplace also reported a strict sense of control. For example, Louise ${ }^{1}$, who worked in administration, described her day as follows:

"I am on the professional grade so I don't have fixed working hours, so I usually roll in about ten past, quarter past nine or so but I tend not to have a lunch break, especially if there are urgent deadlines to meet, and I usually work until half past six or so at night. Sometimes I come in at weekends, and I work from home as well... It is very flexible but nevertheless I do a minimum of seven and a half hours a day in the office and sometimes I do work from home remotely too."

Louise's case was typical in that virtually every single interviewee of 'professional grade ${ }^{2 \text { ' }}$ stressed that, whilst they did not have particular working hours stipulated in their contracts, the 7.5 hour day was worked as a minimum - often with considerable home working undertaken in addition. PhD students - who also do not have prescribed 'working hours' - also placed an emphasis on the need to control their working day in ways which they considered to be the most 'productive': managing their emails, scheduling tasks and prioritizing different work streams in ways they felt

\footnotetext{
${ }^{1}$ Pseudonyms have been used throughout to provide anonymity.

2 At Lancaster University, all employees hired on grade 7 and above have contracts which state that "fixed working hours are not specified and working time is that reasonably required to fulfil the duties of the appointment".
} 
This is a pre-copy-editing PDF of an article accepted 20 Sep 2013 following peer review for publication in Environmental Values 24 (2015): 581-601. doi: 10.3197/096327114X13947900182111

(C)The White Horse Press http://www.whpress.co.uk

most 'efficient'. For example, in relation to a discussion about different working styles, Grace, a $\mathrm{PhD}$ student, said:

"I used to multi-task quite a lot but in the last sort of month or so I've actually tried to do a task, complete it and then move on to the next one, just because my brain can't keep up... I'm a bit more efficient if I do that." (Emphasis mine)

Katy, who worked in business outreach, had also tried to block out tasks but found that: "it didn't really work for me. I'm much more of a reactive person so I basically respond to them [requests, emails] as they come in”. However, whilst multitasking suited her better, she remained undecided about how successful it was in terms of her actual work, admitting that it was "probably not the most productive way of doing it but it seems to work for me." (Emphasis mine).

Of course, what constitutes 'productivity' or 'efficiency' at work is a controversial subject which goes beyond the remit of this paper. However, the key point in relation to the present discussion is that, while the university appears to offer a very flexible working environment, there is also a high level of control attached to this freedom which is not restricted to the simple and traditional top-down rule of manager over employer. Instead, it appears to operate through the much more subtle mechanism of self discipline with employees evaluating - and reflexively re-formulating their working practices in response to how 'productive' or 'efficient' they felt they were being. Such self governance was apparent in the amount of striving that went on - for example, people would talk a lot about "trying" to do particular things - such as trying to be "disciplined", or setting particular "policies" for themselves in terms of how they would look to do things.

To try and understand this situation I turned to the governmentality literature and the idea that “individuals are to be governed through their freedom” (Miller and Rose, 2008 p.25). Drawing on Foucault (1982, 1980, 1991, 1995), Miller and Rose's work (2008) has provided a useful tool 
This is a pre-copy-editing PDF of an article accepted 20 Sep 2013 following peer review for publication in Environmental Values 24 (2015): 581-601. doi: 10.3197/096327114X13947900182111

(C)The White Horse Press http://www.whpress.co.uk

for writers and thinkers the world over through its analysis of how early modern forms of government, where power was exercised centrally through laws, coercion or violence, differ from the advanced neo-liberal forms of rule that are evident in many situations today. For instance, we know that neoliberal control operates much more subtly by producing particular kinds of self-disciplining citizens who, effectively, internalise the values and norms of modern life and thus mould themselves into the kinds of people who are useful to 21 st century society. In effect, then "freedom has become, in our so-called 'free societies', a resource for, and not merely a hindrance to, government.” (Barry et al., 1996 p.8)

We also know that particular norms and ideas are key to this form of governance, including the reification of economic forces: the idea that competition is inherently good, that price and value for money are the best basis for decision-making and that services are most effectively delivered through the market. A further example is the concept of the self-made, active individual citizen who, rather than looking to the government, family or friends for help, must accept responsibility for their own fortunes in life (Rose, 1999b, Rose, 1999a).

"This is an ethic in which the maximization of lifestyle, potential, health and quality of life has become almost obligatory, and where negative judgements are directed toward those who will not, for whatever reason, adopt an active, informed, positive and prudent approach to the future.” (Rose, 2006 p.25)

The idea of the individual as a free agent who stands alone and must work actively on themselves to make their own luck - preferably through the market - is one that we know operates across all areas of society, from education to health, and even the human body itself (Rose, 2006, Bordo, 2003). Indeed, David Cameron’s ‘Big Society’ rhetoric (Conservative Party, 2013), which has already provoked much debate and criticism (Kisby, 2010, Evans, 2011), provides an excellent illustration of these principles at work. 
This is a pre-copy-editing PDF of an article accepted 20 Sep 2013 following peer review for publication in Environmental Values 24 (2015): 581-601. doi: 10.3197/096327114X13947900182111

(C)The White Horse Press http://www.whpress.co.uk

In the context of our present discussion about the 'productive' and 'efficient' employee such ideas can help explain the rise of modern workplace that we see today. In contrast to the industrial revolution model where workers would be heavily supervised and disciplined on the factory floor, Rose (1999a) has shown the contemporary workplace to be characterized by a discourse in which it is up to the individual employee to seek meaning and fulfilment through employment. This is achieved through a number of 'techniques/tools', from self help books to career coaching and professional development workshops whereby the autonomous and self motivated individual is urged to progress. Thus no immediate supervisor is needed since social norms - such as that of the fulfilled and successful employee - are internalised by individuals. These norms are then taken up as a personal project by employees who discipline their bodies and minds in order to fashion themselves into the 'ideal' employee whose goals mirror those of the workplace and society at large. Returning to the interview findings, then, 'productivity' and 'efficiency' can provide a benchmark for a kind of neo-liberal self governance through which we try to re-fashion ourselves into 'better' employees.

However, this raises the important question of how this self governance is experienced by the employees concerned. This is of central importance since the interviews revealed workplace self governance to be strongly emotional in tone.

In the following section I develop the idea of governance by and through the emotions before going on to consider how the environment features as part of this debate.

\section{Workplace governmentality and emotion}

The governmentality literature discussed in the previous section is not commonly linked to the large body of work that exists on the role of emotion in organizational contexts. This is surprising given that much of the latter is concerned with the regulation, control and production 
This is a pre-copy-editing PDF of an article accepted 20 Sep 2013 following peer review for publication in Environmental Values 24 (2015): 581-601. doi: 10.3197/096327114X13947900182111

(C)The White Horse Press http://www.whpress.co.uk

of particular emotional expressions in particular social and organizational contexts - which would seem to be a classic example of governance at work if ever there was one.

For example, Rafaeli and Worline (2001) have commented on what appears to be a growing trend towards institutions trying to create or control particular emotional cultures as a crucial part of their identity. They argue that emotion is now a key element of any organization and that it forms a mechanism through which employers manage their staff and the workplace culture (Lindebaum, 2012). In this way "feeling and display of emotions in organizations can be argued not only to manifest but also to reify organizational structure and patterns" (Rafaeli and Worline, 2001 p.105). There are thus clear echoes here of Rose's (1999a) analysis of the emergence of the contemporary employee: once the employee comes to share the dreams and wishes of the employer, so the theory goes, it will no longer be necessary for there to be the strict, top-down control of manager over subordinate, since the employee will discipline him/herself in service of these shared goals. Either way, it is clear that these literatures are shot through with governance - both in the creation of emotional norms for the workplace and also in the expectation that employees will take it upon themselves to present the appropriate emotion at the appropriate time.

A key concept in this regard is Arlie Hochschild's idea of emotional labour (Hochschild, 1979, Hochschild, 1983). Focusing particularly on the service industry, Hochschild argues that many employees must portray particular emotions that are expected of them during encounters in the workplace. For example, air hostesses must always portray a friendly and welcoming demeanour, while nurses must present an attitude of caring and concern. Hochschild demonstrates that providing such a performance is not only skilful - it also requires a huge amount of work - quite literally, emotional labour. This 'work' is not just mental but physical, since other authors have demonstrated that emotions are bodily as well as cognitive in character (Overing and Passes, 2000, Leavitt, 1996). Hochschild's ideas have not been accepted uncritically (Ogbonna and 
This is a pre-copy-editing PDF of an article accepted 20 Sep 2013 following peer review for publication in Environmental Values 24 (2015): 581-601. doi: 10.3197/096327114X13947900182111

(C)The White Horse Press http://www.whpress.co.uk

Harris, 2004). Nevertheless, the idea of a desired relationship between the workplace and particular kinds of emotional expression has been very helpful for many researchers. For example, Ogbonna and Harris's (2004) study of the increasing marketization of universities shows that, as workloads have intensified and controls on lecturers have been tightened (through auditing processes such as research assessment exercises and student feedback scores), academics are increasingly having to engage in emotional labour as a routine part of their jobs. Whilst not approached from a governmentality perspective, there are some striking parallels with literatures on the regulation of the self as the authors found that, in many cases, despite experiencing considerable stress and frustration, lecturers were internalising this requirement to emotionally labour as simply part and parcel of promoting a 'professional' attitude to their jobs. Equally, Fineman and Sturdy (1999) draw on Goffman's ideas about the importance of 'correct' presentation of the self to show that emotions are not just something that has to be controlled at work. Rather, they are themselves absolutely crucial to the control process. Using a case study of the relationships between Environment Agency inspectors and industrial managers they show that inspectors 'prepare' themselves mentally for the encounter and then attempt to project the right mixture of authority and collaboration - all the while responding to the particular emotions and expectations of the industry manager that they were inspecting.

This idea of self governance as something that operates relationally, by and through the emotions, was a key theme to emerge from the interviews, which revealed how managing the self and the emotions was a crucial aspect of life in the workplace. This applied to the management of 'productivity' (for example, feeling 'bad' about getting distracted by social networking sites at work) and many other aspects of workplace life. Shared offices, for example, were often associated with a lot of anger and frustration which was intensely felt but rarely vocalised. People who would alter the temperature of the room without consulting others, listen to music too loudly through headphones, or conduct meetings and private conversations in the office without 
This is a pre-copy-editing PDF of an article accepted 20 Sep 2013 following peer review for publication in Environmental Values 24 (2015): 581-601. doi: 10.3197/096327114X13947900182111

(C)The White Horse Press http://www.whpress.co.uk

considering those who were trying to concentrate were particular causes of anger. Yet it wasn't just fellow colleagues who incited such feelings - frustration was also experienced in relation to objects and infrastructures, with typical examples being the computer crashes, printer jams and bureaucratic online forms that you must fill in for various aspects of university business. This is not to imply that work was associated only with negative emotions, since certain tasks were found to be enjoyable or rewarding and interaction with colleagues was often highly valued and energizing. However, these positive emotions also required managing - for example, it was often necessary to place limits on the amount of social interaction in order to complete more solitary tasks, while exciting and positive discussions with colleagues about potential new projects also had to be kept in check if unrealistic workloads weren't to emerge as a result.

To summarize, then, the interviews revealed the extent to which emotion was both the subject of - as well as a vehicle for - forms of control and self governance at work which are intrinsically relational in nature. The next section takes our discussion one step further by exploring the specific question of what happens when new expectations around environmental concern enter the picture. Exploring this example allows us to foreground the link between the emotional labour that is carried out in organizational contexts and emerging forms of environmental self control at work.

\section{Environmental governance at work}

Sarah Marie Hall (Hall, 2013)makes the important observation that, when it comes to energy consumption, the majority of discussions centre around the sustainability of such practices, rather than the ethical or moral aspects of such consumption. However, she highlights an important exception to this in Butler's (2010) work on morality and climate change, which provides an excellent illustration of the ways in which environmental governance can operate through ethics and morality. Drawing on focus group discussions with the British public, she 
This is a pre-copy-editing PDF of an article accepted 20 Sep 2013 following peer review for publication in Environmental Values 24 (2015): 581-601. doi: 10.3197/096327114X13947900182111

(C)The White Horse Press http://www.whpress.co.uk

argues that seemingly small actions such as forgetting to turn the TV off of standby, failing to recycle a milk bottle or taking a flight in order to get to a holiday destination have, for some people, become loaded with guilt and judgement. Her findings were supported by our interviews which highlighted the entry of a new form of environmental governance in the workplace. For example, Tim, an IT engineer said "I'm trying to train myself to switch it [office computer] off, but it doesn't always work". Equally, Louise, the administrator that we met earlier explained: "I try to be energy conscious. If I go out at night and if there are still lights on in the seating area here I'll go round and switch all the lights off'.

This was interesting given the broader institutional context. When the interviews were conducted in late 2011, Lancaster University had many environmental infrastructure projects in progress, including the installation of a wind turbine, a new CHP (combined heat and power) plant and biomass boiler. It also had a well developed Carbon Management Plan (Lancaster University, 2011) and a history of staff engagement around sustainable transport issues. However, there had not yet been any kind of formalised staff 'behaviour change' campaign around the subject of reducing energy consumption on campus. Despite this, the interviews made it clear that the environment was becoming a subject for yet more 'trying' and self discipline as interviewees attempted to adopt a range of micro-practices that they saw as being eco friendly.

Just as we saw with the kinds of self governance exhibited around productivity and efficiency, this environmental self governance was distinctly emotional and moral in tone. For example, Raphael talked about wanting to do the "right thing", while Will described his "ethics to be energy efficient". Even Luke and Geoff, who specifically described themselves as not environmental 'types', reported taking actions to try and help the environment where possible. In trying to live up to this ideal of the environmentally conscious citizen, there was a lot of trying and striving. As we saw with the productive employee example, there were also shades of guilt and judgement when these efforts failed, as interviewees variously described themselves in 
This is a pre-copy-editing PDF of an article accepted 20 Sep 2013 following peer review for publication in Environmental Values 24 (2015): 581-601. doi: 10.3197/096327114X13947900182111

(C)The White Horse Press http://www.whpress.co.uk

morally and emotionally loaded terms. For example, Geoff described himself as being "a bugger in one sense because I never turn my computer off... because... I might want to just go in and work on something [via remote desktop]", though he also "tried" to remember to turn the printer off. Equally, Katy recounted how "I used to be quite good [at turning her computer off for the weekend]; I've got a bit slack recently".

It could be argued that it is important not to overstress the emotional significance of these self judgements. Despite the fact that I stressed to interviewees that there were no 'right' or 'wrong' answers, they knew that the project was about energy use in the workplace and therefore it is possible that they felt they should make judgements about themselves. However, the interesting thing is that they recognised micro-practices like lighting, heating and printing as subjects for self governance and moral judgement in the creation of environmental employees in exactly the same way as they recognised working practices like email management as being necessary topics for governance and morality in the creation of efficient, productive employees.

Crucially, however, the research literature and interviews also highlighted the potential for social conflict resulting from these new environmental governmentalities. For example, Hargreaves' (2010, 2012, 2013, 2014 in press) work on smart meters in the home shows that such technologies are creating new forms of surveillance and environmental discipline since they allow householders to monitor not just their own consumption but also that of fellow household members. Hargreaves describes how conflicts can arise within the household since men, in particular, tended to take the most interest in the smart meter, meaning that they ended up 'policing' the consumption of the household. This frequently led them into judgemental relationships with women and children, who were criticised for leaving lights on or using appliances in particular ways which were perceived to be more energy intensive. However, the research also showed that there were definite limits to the governance of the smart meter within the home as householders would simply ignore the meter's feedback when it was perceived to 
This is a pre-copy-editing PDF of an article accepted 20 Sep 2013 following peer review for publication in Environmental Values 24 (2015): 581-601. doi: 10.3197/096327114X13947900182111

(C)The White Horse Press http://www.whpress.co.uk

contravene the 'need' to perform a particularly indispensible practice. For example, things like dishwasher use, TV viewing and computer usage were perceived as a necessary part of what it meant to be able to lead a 'normal' life and, when the smart meter reminded residents of the energy implications of these practices, they often became angry and defensive and rejected its 'gaze' (Hargreaves, 2014 in press, Hargreaves et al., 2013). Thus whilst it may result in some initial 'quick wins' when it is first introduced to the household, Hargreaves' work shows that, in the longer-term, the smart meter may actually be cementing particular energy consuming household practices as 'normal', 'necessary' and beyond guilt or debate.

This example is particularly interesting in the context of this paper since it underlines the crucial fact that both governance processes and the emotions are inherently relational - that is an integral part of how we interact with the people and objects around us on a daily basis. Understanding this relationality is vital for practitioners and policy makers interested in environmental issues, since it can help explain why simplistic behaviour change models which are focused at the level of the individual (for example, the kinds of approaches that Shove describes as the $\mathrm{ABC}$ of policy making (2010), where attitudes lead to a change in behaviour and thus in the consumer choices that people make) struggle to achieve the desired level of change and can create conflict between people. For example, whilst feelings of 'guilt' or 'wanting to do better' sometimes motivated interviewees to modify certain elements of their own practices, these feelings appeared largely incapable of changing the practices of those around them. As a result, interviewees described strong feelings of anger and resentment towards colleagues who appeared to be making no effort to consider the environment. For example, Kerry said:

"At home I'll go around and turn everything off. I only feel at work I can only do my own stuff; I can't go around at the end of the day and turn everyone else's off. But it does infuriate me if people just go and leave their computer on but... then when you are in an office it's all 
This is a pre-copy-editing PDF of an article accepted 20 Sep 2013 following peer review for publication in Environmental Values 24 (2015): 581-601. doi: 10.3197/096327114X13947900182111

(C)The White Horse Press http://www.whpress.co.uk

communally controlled you know, with the lights they are either all on or you're in the dark. So

I'd like to do a bit more but it's not for my say so to make everyone sit in the dark."

Lee's annoyance and criticism also extended to those who continued to drive to work: "I still hear a few people who complain about the parking on campus or you know that it costs you or whatever. And I say, 'I [don't] know what your problem is, I always take the bus, why can't you?... What, you can't walk ten minutes to the stop? What is your problem exactly?" You know, or cycle, which I often do.”

These sentiments seemed to be fairly typical of environmentally conscious employees - they were intensely aware, and often intensely irritated, by their colleagues' failure to exercise self discipline when it came to the environment but felt that there was nothing they could do to change this. Of course, as described previously, this judging of one's colleagues adds to what is already a complex emotional picture, particularly in shared office contexts where anger, irritation and resentment already simmered under the surface in relation to those who were perceived to be inconsiderate in relation to noise, temperature or their use of space. However, once again it appeared that a huge amount of emotional labour was being used to manage such emotions since, as with other aspects of office irritation, anger was rarely - if ever - vocalised directly or translated into action: for most people, challenging someone openly or taking responsibility for another person's equipment would be unthinkable. This finding was also noted in Hargreaves' study of pro-environmental behaviour change initiatives in the workplace (2008). He comments that people often held very strong moral judgements on their colleagues' behaviour. However, before an environmental champions initiative, such feelings were rarely vocalised or translated into practice except through very 'indirect' methods, such as an accusatory email to remind everyone of their responsibility to recycle, after recyclable items were once again found in the wrong bin. 
This is a pre-copy-editing PDF of an article accepted 20 Sep 2013 following peer review for publication in Environmental Values 24 (2015): 581-601. doi: 10.3197/096327114X13947900182111

(C)The White Horse Press http://www.whpress.co.uk

Interestingly, in my research, the interviews showed that anger also extended beyond the behaviour of particular colleagues to encompass non human aspects of the campus infrastructure that were seen as making a mockery of efforts to save energy. For example, Claire commented on the automatic doors "letting out ridiculous amounts of heat every time someone wants to come into a building.... So that actually really annoys me... Stupid and wasteful.” Equally, Steph was annoyed at the new monitor on her computer, which did not appear to have a button to enable it to be switched off: "I find it annoying that the design of the product is so poor when it comes to... energy use and things. This whole issue of standby and whatever and not having proper buttons to switch it on and off."

Consequently, many interviewees appeared to be experiencing a lot of anger and resentment that their own good intentions in relation to energy governance were being thwarted by the people and infrastructures around them.

However, it is vital to remember that these new forms of governance which result from emerging expectations around environmental concern do not enter a vacuum. In the next section, I continue our focus on governance and emotion to explore what happens when 'new' environmental governmentalities enmesh (Hargreaves, 2008) with existing forms of governmentality that relate to the 'productive' and 'efficient' employee.

\section{Conflicts between the governance of productivity and the governance of the environment?}

As I have noted previously, environmental interventions such as smart meters in the home or pro-environmental behaviour change initiatives in the workplace can create new forms of discipline and surveillance, with the effect that previously highly personal practices - such as how long someone showers for or whether they print double sided at work - become politicised and subject to control and intervention. However, crucially, the literature notes that these new forms 
This is a pre-copy-editing PDF of an article accepted 20 Sep 2013 following peer review for publication in Environmental Values 24 (2015): 581-601. doi: 10.3197/096327114X13947900182111

(C)The White Horse Press http://www.whpress.co.uk

of governance do not necessarily replace pre-existing forms of governance at home and at work - rather, they enmesh with them in interesting and sometimes unpredictable ways (Hargreaves, 2008). For example, Hargreaves' study of pro environmental behaviour change initiatives in the workplace (2008) showed that such measures were interacting with existing forms of workplace discipline which affected what it meant to be considered a 'good' employee. His work thus suggests that we need to pay attention to the ways in which these different forms of power come together.

This finding was very much supported by the interviews which revealed that some very interesting interactions were occurring around the intersection of environmental self governance with the productive, efficient, work ethic. These findings once again illustrate the well known argument that a simple change in attitude or emotion (such as feeling guilty) does not necessarily result in changed practices (Shove, 2010). For example, whilst Katy felt guilty for forgetting to turn off her screens, she did not feel guilty for using two screens in the first place, or for replacing her computer regularly because, as she explained to me: 'Well I think you've got to be kind of realistic that it's the modern age and a lot of stuff is done electronically and done over the Web so people do need computers. And they need them at high spec, they need to run fast. So there is going to be wastage in terms of replacing computers."

Indeed, the trend towards more people using two screens in the workplace and also owning increasing numbers of electronic devices (perhaps a laptop, dual screen desktop, iPad and smart phone) was rarely seen as a subject for guilt because it was simply viewed as a necessary part of the modern workplace and what it was to be a productive employee. As Geoff explained: "If I had to put a figure on it, I'd say your productivity goes up 20 per cent - it's amazing". Clearly, there is a whole separate argument here about the co-production of need, technology and 
This is a pre-copy-editing PDF of an article accepted 20 Sep 2013 following peer review for publication in Environmental Values 24 (2015): 581-601. doi: 10.3197/096327114X13947900182111

(C)The White Horse Press http://www.whpress.co.uk

expectation - itself a subject of immense importance in relation to the environment ${ }^{3}$. However, the key point in the context of this paper is that a focus on emotion - or, perhaps more tellingly, its backgrounding in particular contexts - can enable us to begin to develop a better understanding of what happens when a new kind of environmental governmentality is introduced into the existing governmentality of the 'productive', 'efficient' workplace. Crucially, we can see how a reflection on the relational nature of emotion adds to this understanding of governmentality since strong reactions can arise in response to seemingly minor aspects of everyday practice in the workplace where emotional responses are not necessarily shared. For example, while having more devices was not seen as a subject for guilt by many interviewees (since it could be justified by an increase in ease, convenience or productivity), others rejected this as unnecessary and stressed the simplicity of their technology needs in the workplace.

Interestingly, however, conflicts between the governance of 'productivity' and the governance of 'environmentalism' emerged more strongly (although not exclusively) in interviews with older interviewees. Typically, such discussions centred around the idea that modern life (including but not exclusively limited to the workplace) involved people wanting to do things more instantaneously, resulting in devices like computers and wireless routers needing to be left on more, since there was no knowing when they might next be needed at a moment's notice. This idea of modern life as somehow 'speeding up', with previously discreet blocks of activity becoming increasingly fragmented and rearranged in real-time, is a popular topic of discussion in geographical and sociological literatures ${ }^{4}$. Interviewees contrasted this to a remembered past in which activities were planned ahead and carried out in blocks and, consequently, it was felt to be easier to determine when something was finished with, thus allowing it to be switched off. Feeling that they had to keep up with contemporary trends for greater availability at a moment's

\footnotetext{
3 The literature on this is vast but see, for example, Shove, E 2003 Comfort, Cleanliness and Convenience: The social organisation of normality Berg, Oxford. for an excellent example of rising expectations of comfort, cleanliness and convenience in relation to personal hygiene, indoor temperature and laundry practices.

4 These literatures are extensive but for some key references see Shove et al., 2009, Castells, 1996, Harvey, 1990.
} 
This is a pre-copy-editing PDF of an article accepted 20 Sep 2013 following peer review for publication in Environmental Values 24 (2015): 581-601. doi: 10.3197/096327114X13947900182111

(C)The White Horse Press http://www.whpress.co.uk

notice seemed to be associated with a sense of guilt and failure in relation to the environment at the same time as they realised that this situation couldn't really be helped. Thus Raphael commented:

"I am concerned about it [energy use] and aware of it and I would like it to be much better. But I think the question is, it's organising your life in the way that if you're more organised I think you can save more energy. But my life isn't terribly organised, partly my fault and partly the way we have to interact with people, it's difficult. But I'm sure you know if there were ways of organising your life much more effectively to save energy... I'm sure it could be well cut down."

This increasing inability to organise and plan ahead was also something that Claire remarked on as she described how difficult it was to turn your computer off on account of the constant expectation that you must be available to answer emails: "You know there's a constant pressure isn't there? ...The perception that you have to answer emails throughout the day because that's the main way that people communicate. If your emails are off then you might miss something whereas if people actually made phone calls then you could switch your computer off."

Thus, in many cases, people seemed to be experiencing feelings of conflict, guilt and failure as their efforts to do better environmentally conflicted with other kinds of trying and striving including the goal of living up to the image of the efficient, productive employee - that were already part and parcel of their everyday work lives. The emotional struggles that go on around competing kinds of governance is not commonly discussed in the environmental literature. However, other research areas have explored this a little more. For example, Susan Pickard (2010) uses a study of caring practices to show how two key aspects of advanced liberal governmentality - specifically, the policy rhetoric endorsing the importance of individual choice when making personal decisions (about care options, for example), and a discourse stipulating the importance of social responsibility within the family and society - can come into direct 
This is a pre-copy-editing PDF of an article accepted 20 Sep 2013 following peer review for publication in Environmental Values 24 (2015): 581-601. doi: 10.3197/096327114X13947900182111

(C)The White Horse Press http://www.whpress.co.uk

competition with each other as people try to make difficult decisions about how best to care for the needs of a sick or elderly family member. She quotes Kleinman (1998) to argue that the complexity of the moral choices that we make are only revealed in the concrete circumstances of everyday life, rather than at the level of abstract principles (Kleinman, 1998) - a theme that is highly relevant for this paper.

Indeed, drawing on a diverse range of theoretical traditions, authors writing about emotion have emphasised that the complex realities and strongly felt uncertainties of modern living often result in our having to perform additional emotional work as there is no longer a rule book or any sense of tradition which defines what might constitute appropriate conduct in many situations (Holmes, 2010). Thus, in outlining the role that emotion plays in reflexivity, Holmes writes that:

"The exigencies of lives within modernity often create confusion and guilt. If connection to others is a matter for design, not tradition, then there are many possibilities but few guidelines." (Holmes, 2010 p.148)

This idea of multiple uncertainties, confusion and guilt in the face of a rapidly changing world is, I would suggest, extremely relevant to the entry of environmentalism into the workplace, with the implication being that such changes are leading to doubt and confusion about what is appropriate and reasonable in these settings. Further evidence for this viewpoint can be found in a small but emerging number of exchanges in academic publications and the wider media where sentiments ranging from uneasiness and doubt through to abject disgust and outrage are expressed at the kinds of conflicts that come into play when, for example, politicians, scientists and other professionals are required to attend international conferences that require increasing amounts of flying in order to meet employers and colleagues' notions of what constitutes a successful professional identity (Hall, 2007, Bonnett, 2006). However, while the tone of these discussions is often highly emotionally charged, these emotional aspects are rarely reflected on 
This is a pre-copy-editing PDF of an article accepted 20 Sep 2013 following peer review for publication in Environmental Values 24 (2015): 581-601. doi: 10.3197/096327114X13947900182111

(C)The White Horse Press http://www.whpress.co.uk

explicitly. Hence I conclude by arguing that is crucial to acknowledge the strong feelings that such situations arouse - and the difficult moral decisions that result - if we are to find a better way forwards.

\section{Conclusions}

This paper argues that the emotions are a crucial part of who we are and how we live and experience our daily lives, both within and beyond the workplace. They are also inherently relational and thus a central part of how we interact with others and the environment. In this way, the micro-practices of everyday life are both political and personal. Once we understand this then we should no longer be surprised to find that something as small as a light left on in an unoccupied office or a recyclable item in the wrong bin can provoke emotions as strong as guilt, rage or despair.

I have also illustrated that the emotions are not only the subject of (Hochschild 1979, 1983), but also a vehicle for governmentality. The process of trying to fashion yourself into both a productive and environmentally conscious employee is a deeply emotional experience involving a daily roller-coaster round of guilt, striving, conflict and frustration which, if you are lucky, will be interspersed with bursts of pride and elation when you feel like you may finally have got things right.

This article also shows what can happen when different forms of governmentality intersect (Hargreaves, 2008). I have argued that the realm of emotional experience forms a key arena in which conflicts between different forms of governance are manifested and played out: hence the experience of not wanting to fly but fearing that our commitment to our work will be questioned if we fail to attend that international conference. Or the anger and guilt that we might experience the day after we forget to turn the lights off in our corridor because we were stressed and running to a meeting, only to find that a group email has been sent reminding us all that 
This is a pre-copy-editing PDF of an article accepted 20 Sep 2013 following peer review for publication in Environmental Values 24 (2015): 581-601. doi: 10.3197/096327114X13947900182111

(C)The White Horse Press http://www.whpress.co.uk

"someone" wasted electricity by leaving the corridor light on all night. My argument is that the research literature, policy initiatives and, indeed, our everyday discussions about work and the environment do not acknowledge nearly enough what it feels like to become involved in - and try to negotiate our way through - these conflicts. Perhaps this neglect is a result of a general historical denial of (albeit certain forms of) emotion in the workplace (Rafaeli and Worline, 2001), or perhaps it is because we feel ashamed that we experience such strong reactions in response to such relatively minor events. However, the main point is that, if we are to find a better way of dealing with the kinds of situations described in this paper then we need to first acknowledge how intensely they are borne and felt - in short, how emotionally strenuous is the work of trying to refashion our subjectivities.

So are there some better way forward? How can these insights help us think about alternative ways of governing work and the environment in the present and future? Clearly this is a task that goes way beyond the scope of this paper. However, I will offer some tentative thoughts on future research questions and additional theoretical perspectives which may prove helpful in this regard...

In terms of future research, one issue which I have barely touched upon is the question of how governance practices and emotional experiences may vary in different kinds of work environments, and with what consequences for workplace environmentalism? Contemporary workplaces vary hugely in their physical and temporal organization, from large open-plan environments to individual private offices (perhaps in the home or a remote location), and from flexible personal scheduling to the traditional nine to five office day. All of the above could have a major effect on the kinds of disciplining practices which may come into play in relation to the environment and productivity. For example, reflecting on changes in the design and organization of contemporary workplaces, Pauline Leonard uses Foucault and Lefebvre to argue that “"green' has frequently become bound up with 'lean' and 'mean' within organizational discourses and 
This is a pre-copy-editing PDF of an article accepted 20 Sep 2013 following peer review for publication in Environmental Values 24 (2015): 581-601. doi: 10.3197/096327114X13947900182111

(C)The White Horse Press http://www.whpress.co.uk

imaginations" (Leonard, 2013 p.333), thus highlighting an area of study that holds much promise for those interested in the connections between emotion, the environment, governance and design at work.

As for new theoretical directions, this paper provides further support to two burgeoning trends within the energy consumption literature. Firstly, its emphasis on the importance of the relationship between power and emotion leads me to echo Sarah Marie Hall's (2013) assertion that concepts of ethics and morality should play a bigger role within studies of energy consumption. In short, we need "a move towards a more nuanced and critically engaged conceptualisation of the link between consumption and morality... to better understand how consumption practices are linked to one another and to broader debates on social and environmental change” (Hall, 2013 p.424).

A related point is that this paper further supports the argument that we need to expand our understanding and practice beyond approaches focused exclusively on individual behaviour change. These approaches, which are currently dominant in policy and everyday understandings, posit that the best way to tackle environmental problems is to provide people with more information about the damaging effects of their behaviour with the assumption that they will change their attitudes towards the environment and thus reorient their behaviour in more sustainable ways (see for example Shove (2010)). This mechanism is not completely without value. However, as this paper illustrates, there will inevitably be clear limits to its effectiveness because it is incapable of accounting for three things: the role played by wider aspects of social and material infrastructure, the emotional and moral significance of our engagement with environmental issues and, thirdly and crucially, the part that power plays in bringing all these aspects together. In the space remaining, I shall briefly examine these aspects in turn while suggesting some further theoretical approaches which may provide helpful tools in these areas. 
This is a pre-copy-editing PDF of an article accepted 20 Sep 2013 following peer review for publication in Environmental Values 24 (2015): 581-601. doi: 10.3197/096327114X13947900182111

(C)The White Horse Press http://www.whpress.co.uk

Firstly, the role of social and material infrastructures. I have argued that expecting the burden of environmental change in the workplace to be born exclusively by individuals is unfair and unrealistic given that it can be very difficult for them to change the energy intensive qualities of the workplace infrastructures around them (for example, the lack of double glazing in the office window or the workplace-wide pressures for more international travel). Here, theories of social practice may be helpful in suggesting alternative points of intervention such as changes to the material infrastructure of the workplace, the skills needed in order to perform work or even the meanings associated with 'work' itself (Shove et al., 2012). Building on the conclusions of this paper, it might be helpful to explore whether focusing on these alternative sites of interventions could help relieve some of the strain which is currently being born by isolated individuals in the workplace.

However, this paper shows that it is equally important not to neglect the deeply emotional and moral experience of engaging with environmental change, which is not generally considered within social practice theory. Here we could, perhaps, gain inspiration from psychosocial approaches to research, of which the Carbon Conversations project is a good example (Carbon Conversations, 2013). Such approaches have their origins in the psychoanalytic approaches developed by Freud and hence stem from a very different theoretical tradition to social practice theory. However, they offer a number of tools which could prove helpful in tackling the kinds of atomising and painful experiences resulting from the work and environment conflicts described in this paper. They are based upon the idea that questions of environmental change provoke powerful emotional and moral responses in us that are both deeply personal and socially shared (Randall, 2005). It follows that one potentially effective way of tackling these responses is to create safe, therapeutic spaces in which these experiences can be tackled collectively(Randall, 2011). For example, in the Carbon Conversations project, which can be applied to both the workplace and the home, small groups of people meet regularly to support each other in working 
towards a lower carbon lifestyle (Carbon Conversations, 2013). A question for future research, therefore, is whether approaches such as these, which are capable of dealing with the emotional and moral significance of environmental change at a collective and personal level, could be combined with practice-inspired approaches which provide a much needed focus upon the infrastructural and material aspects of change.

All this brings us back to the crucial question of power which, as we have discussed in this paper, plays an integral part in our personal and emotional relationships with each other and the infrastructures that surround us, both at work and at home. Building on the relational and emotional approach to governmentality developed here, future research might consider whether a focus on everyday social practices can help improve our understanding of the ways in which governmentality operates. By performing a particular environmental practice, such as recycling or cycling to work, are we effectively disciplining others by illustrating that this is the 'correct' way of performing in that particular situation? A relational approach to governmentality suggests that the connections between what may appear to be a very 'personal' practice and what we recognise to be more widely shared 'social' practices could be a fruitful subject for investigation in efforts to encourage a shift towards more environmental lifestyles.

\section{Acknowledgements}

I would like to thank the interviewees and the carbon management team at Lancaster University for their generosity in sharing their experiences with me. Special thanks also go to Rebecca Ellis for her invaluable guidance and support in producing this paper, to Kevin Burchell and the two anonymous reviewers whose insightful comments really helped improve its key arguments and, finally, to the EPSRC for funding 'Current'.

\section{References}


This is a pre-copy-editing PDF of an article accepted 20 Sep 2013 following peer review for publication in Environmental Values 24 (2015): 581-601. doi: 10.3197/096327114X13947900182111

(C)The White Horse Press http://www.whpress.co.uk

Barry, A, Osborne, T \& Rose, N 1996 Introduction. in Barry, A, Osborne, T \& Rose, N eds Foucault and Political Reason. Routledge, Abingdon

Bonnett, A 2006 The need for sustainable conferences. Area 38 229-30.

Bordo, S 2003 Unbearable weight: feminism, Western culture, and the body University of California Press, Berkeley.

Butler, C 2010 Morality and Climate Change: Is Leaving your TV on Standby a Risky Behaviour? Environmental Values 19 169-92.

Carbon Conversations 2013 What is Carbon Conversations? (http://carbonconversations.org/whatcarbon-conversations) Accessed 18th September.

Conservative Party 2013 Big Society (http://www.conservatives.com/Policy/Where we stand/Big Society.aspx) Accessed 17th April.

Evans, K 2011 'Big Society' in the UK: A Policy Review. Children \& Society 25 164-71.

Fineman, S \& Sturdy, A 1999 The Emotions of Control: A Qualitative Exploration of Environmental Regulation. Human Relations 52 631-63.

Foucault, M 1980 Power/knowledge Pantheon Books, New York.

Foucault, M 1982 The Subject and Power. Critical Inquiry 8 777-95.

Foucault, M 1991 Governmentality. The Foucault Effect. University of Chicago Press, Chicago.

Foucault, M 1995 Discipline and Punish: The birth of the prison Vintage, New York.

Glaser, B 1992 Basics of grounded theory analysis Mill Valley CA Sociological Press.

Hall, E 2007 Alternative futures for academic conferences: a response to Bonnett. Area 39 125-29.

Hall, S M 2013 Energy justice and ethical consumption: comparison, synthesis and lesson drawing.

Local Environment 18 422-37.

Hargreaves, T 2008 Making Pro-Environmental Behaviour Work: An Ethnographic Case Study of Practice, Process and Power in the Workplace. University of East Anglia.

Hargreaves, T 2012 Governing Energy Use at Home: Smart meters, governmentality and resistance (http://www.3s.uea.ac.uk/sites/default/files/2012-

01\%20Hargreaves\%20Governing\%20energy\%20use.pdf) Accessed.

Hargreaves, T 2014 in press Smart meters and the governance of energy use in the household. in Stripple, J \& Bulkeley, $\mathbf{H}$ eds Governing the climate: new approaches to rationality, power and politics. Cambridge University Press, Cambridge.

Hargreaves, T, Nye, M \& Burgess, J 2013 Keeping energy visible? Exploring how householders interact with feedback from smart energy monitors in the longer term. Energy Policy 52126 34.

Hargreaves, T, Nye, M. ,Burgess, J. 2010 Making Energy visible: A qualitative field study of how householders interact with feedback from smart energy monitors Energy Policy 38 6111-19.

Hitchings, R 2012 People can talk about their practices. Area 44 61-67.

Hochschild, A 1979 Emotion work, feeling rules and social structure. The American Journal of Sociology 85 551-75.

Hochschild, A 1983 The managed heart: Commercialization of human feeling University of California Press, Berkeley.

Holmes, M 2010 The Emotionalization of Reflexivity. Sociology 44 139-54.

Kisby, B E N 2010 The Big Society: Power to the People? The Political Quarterly 81 484-91.

Kleinman, A 1998 'Experience and its moral codes: Culture, human conditions and disorder'. Tanner Lectures on Human Values, Stanford University, April 12-16.

(http://www.tannerlectures.utah.edu/lectures/documents/Kleinman99.pdf) Accessed April 17.

Lancaster University 2011 Carbon Management Plan 2009-2012 (http://www.lancs.ac.uk/estates/documents/CMP/Carbon\%20Management\%20Plan.pdf) Accessed 25th July 2012. 
Leavitt, J 1996 meaning and feeling in the anthropology of emotions. American Ethnologist 23 51439.

Leonard, P 2013 Changing Organizational Space: Green? Or Lean and Mean? Sociology 47 333-49.

Lindebaum, D 2012 I Rebel-Therefore We Exist: Emotional Standardization in Organizations and the Emotionally Intelligent Individual. Journal of Management Inquiry 21 262-77.

Miller, P \& Rose, N 2008 Governing the Present: Administering Economic, Social and Personal Life. Polity, Cambridge.

Ogbonna, E \& Harris, L C 2004 Work Intensification and Emotional Labour among UK University Lecturers: An Exploratory Study. Organization Studies 25 1185-203.

Overing, J \& Passes, A 2000 Introduction: Conviviality and the opening up of Amazonian anthropology. in Overing, J \& Passes, A eds The Anthropology of Love and Angeer: The aesthetics of conviviality in Native Amazonia. New York, Routledge.

Pickard, S 2010 The 'Good Carer': Moral Practices in Late Modernity. Sociology 44 471-87.

Rafaeli, A \& Worline, M 2001 Individual emotion in work organizations. Social Science Information 40 95-123.

Randall, R 2005 A new climate for psychotherapy? Psychotherapy and Politics International 3 16579.

Randall, R 2011 Is it Time to Stop Talking about Behaviour Change? Summary of presentation made at the conference 'Future Climate 2', Institution of Mechanical Engineers September 23rd 2011 (http://rorandall.files.wordpress.com/2012/09/is-it-time-to-stop-talking-aboutbehaviour-change-v2.pdf) Accessed 18th September.

Rose, N 1999a Governing the Soul: The Shaping of the Private Self Routledge, London.

Rose, N 1999b Powers of Freedom: Reframing Political Thought Cambridge University Press, Cambridge.

Rose, N 2006 The Politics of Life Itself: Biomedicine, Power, and Subjectivity in the Twenty-First Century Princeton University Press, Princeton.

Shove, E 2003 Comfort, Cleanliness and Convenience: The social organisation of normality Berg, Oxford.

Shove, E 2010 Beyond the ABC: climate change policy and theories of social change. Environment and Planning A 42 1273-85.

Shove, E, Pantzar, M \& Watson, M 2012 The Dynamics of Social Practice: Everyday life and how it changes Sage, London. 